\title{
Psycho-social aspect encountered by health professionals in work environment at primary health care centers in Dammam city
}

\author{
Abrar Bani Bakhsh* \\ Nursing College, Community Health Nursing. King Saud University, Riyadh, Saudi Arabia
}

Received: April 1, 2021

DOI: $10.5430 /$ jnep.v11n12p17

\author{
Accepted: June 16, 2021 \\ Online Published: January 10, 2021 \\ URL: https://doi.org/10.5430/jnep.v11n12p17
}

\begin{abstract}
Background and objective: Psychosocial aspects may affect workers and the quality of care given. It has a negative impact in psychological state of the healthcare providers, such effects causes lack of healthcare quality and enforcing healthcare workers to leave work in primary centers. This study aims to explore the psychosocial aspect encountered by the health professionals as related to their work environment at primary healthcare centers in Dammam City.

Methods: This study adopts a descriptive quantities research methodology cross-sectional and correlative design used. convenient subjects among 300 participants of health professionals.

Results: A group of 300 health professionals were participated in this study. They included doctors, nurses, pharmacist, allied health personal, above half of them were females (54.3\%), married (77\%), diploma degree (50.7\%). Nurses were the highest rate of health professionals (34\%). In psychological aspect, the highest mean of employees were affected by their passion with client at work (Highest Mean: 3.78). The work for them was valuable and important (Highest Mean: 4.36). In social aspect, the researcher found that colleagues tend to hear each other and sharing problems concerning their work or life issues with each other more than with managers or supervisors (Highest Mean: 4.11). In relation to the work environmental aspect, the researcher found that the nature of their work situation needs them to complete their work quickly with extra speed (Highest Mean: 4.06). They work more than 8 hours per day (Highest Mean: 3.49), there is no variation in the work performed. The same task repeated daily (Highest Mean: 4.16). They were influenced by the state of their families and friends. They work a lot of time (Highest Mean: 3.91).

Conclusions: The participants of this study mainly female, nurses and married staff members, participants mostly complain work environment which put them in emotional disturbed situation. The Psychosocial aspects sometimes potentiate healthcare providers experiences. They tend to overcome bad situation in their work places. The researcher found that most of the participant seek social support and help which is importance aspects for them to perform their jobs accurately as required. It is obvious that stress experience, pressure and exhaustion in work environment for period of time, will lead to bad services provided by healthcare staff members. The result of the study led us to consider the practice of healthcare professionals in their work environment in Dammam City in KSA. In fact, the adoption process and procedures followed to reach the significant results which enhanced the role of the healthcare staff members.
\end{abstract}

Key Words: Psychosocial, Aspects, Work environment, Challenges, Emotion, stress, Health professional, Primary health care

\footnotetext{
*Correspondence: Abrar Bani Bakhsh; Email: abrarbaksh1990@ gmail.com; Address: Nursing College, Community Health Nursing. King Saud University, Riyadh, Saudi Arabia.
} 


\section{INTRODUCTION}

Indeed, primary healthcare is very important part for community health. Its usually offered by family physician, community nurses and medical staff in local clinics, or by other health professionals. It should be universally accessible to individuals and families by means acceptable to them at af fordable cost that the community and country citizens can bear. ${ }^{[1]}$

This study is important in health scope, it intended to seek problems facing healthcare providers in specific care centers in Dammam City and to recommend solutions to these problems, taking in to account that Primary Health Care Centers (PHCs) are distributed throughout all cities, covering all areas according to the Ministry of Health statement in the Kingdom of Saudi Arabia. Generally, a good healthcare system vision serve to provide clients with high level of care, including but not limit, the prevention of thickness before its occurrence, diagnosing it, and treatment of diseases. Therefore, healthcare professionals play a major role in this process, as well as, their allied health professionals such as physicians, dentistry, midwifery, nursing, medicine, optometry, audiology, pharmacy, psychology, and many other health professionals specialized in the field. These care services offered at different stages considered as primary, secondary or tertiary healthcare in public health sector. ${ }^{[2]}$

Health professionals at primary healthcare level are often subject to the impact of stress due to the nature of their work conditions, they were normally suffering pressure, and stress. the matter that affected negatively upon health staff members, especially nurses because they deal with clients directly. ${ }^{[3]}$

One could say that, primary healthcare centers in Saudi Arabia considered as best places offering healthcare for individuals, families, and community, in terms of facilities and equipment. These healthcare centers serve population living in its surrounding areas whether they are Saudi Nationals or non-Saudis Nationals as well. In each healthcare center, there is a highly skilled staff members (Health professionals) consist of nurses, physician, dentists, assistants and coordinators, all of them facing psychological difficulties preventing them to do their jobs properly. Work environment is very important part in health circle because it is the place where the service is supposed to be provided, therefore it should be an interested place. Accordingly, this study aims to help healthcare providers to solve certain problems facing them in their work environment.

Based on the study findings the researcher stated his recommendations and suggestion to be addressed and implemented for better services offered in healthcare centers throughout the Kingdom of Saudi Arabia.

\subsection{The study problem}

In fact, healthcare providers in their work environment may suffer many difficulties, pressures, tension and anxiety in dealings with patients. This situation causes great psychological and social problems impacts healthcare staff members, quality of healthcare provided, and this constituted negative effects in terms of psychological state of healthcare. Therefore, this study tends to find out these obstacles and reduced it if not resolved its causes. Otherwise, these obstacles may lead to professionals to leave jobs at healthcare centers, which may lead to shortage in staff and lack of care for patients in need. Also, problems facing staff classified of in terms of (Psychology - sociology - traditions and customs gender segregation) these aspects reflect the important issues encountered in healthcare sectors. Knowing these obstacles constitutes the bases to prevent its occurrence in healthcare centers to allow the staff members performing their jobs in a better way. By Reliance on these facts the healthcare centers in Dammam city in Kingdom of Saudi Arabia have such problems preventing them to do their jobs easily as it should be. Therefore, here are some supposed psychological and social problems, for which this study seeks to find appropriate and effective solutions. Consequently, the study problem is summarized in the following questions:

1) What is the socio-demographic profile of the healthcare professional included in this study?

2) What are the psychological aspects reported by the healthcare professional?

3) What are the social aspects reported by healthcare professionals?

4) What are the psychosocial aspects related to work environment mentioned by the study participants?

5) Is there any relationship between the socio-demographic, environmental, psychosocial profile and work environment of the professionals participating in the study?

\subsection{Significance of the study}

Healthcare system is important for all aspects of life in promoting the general physical, mental health and well-being of people around the world. It contributes to the economy, industry and to human development as well. The psychosocial aspect for health providers plays main role in health services, whenever health staff serve in a good health condition this would be reflected in their behaviors and in dealing with health centers visitors. Moreover, positive work environment prevent conflict and problems in the work. In addition to that, good psychosocial mood of healthcare providers is useful in primary care, it will be reflected in increasing the quality of care given to the clients and reducing bad effects consequences. Therefore, the psychosocial aspects are very important issue. It may affect positively or negatively on the 
quality of healthcare. Moreover, in how individuals perceive their quality of life. ${ }^{[4]}$

The significance of this study in highlighting the psychosocial aspects, because it has a very high impact on primary healthcare workers. Addressing this issue will allow the health professionals to reform their jobs in a healthy working environment, in order to minimize influences of the work conflicts which may occur due to poor psychosocial aspect in healthcare environment. In one hand, this research will help professional workers in primary healthcare to overcome different obstructions facing them in their work, and impacted their work performance. In other hand this no doubt will be reflected on client's health case. Healthcare system in Saudi Arabia designed to prevent diseases through a regular reformation process. Accordingly, this study is significant because it shed light and focuses on aspects affecting healthcare workers. This significance emerges from the nature and scope of the study.

\subsection{The aims of study}

This study aims to explore and to identify the psychosocial aspect encountered by health professionals in relation to their work environment in primary healthcare centers at Dammam city, Saudi Arabia. Hence, it tries to figure out how to develop and improve healthcare sectors environment to allow the healthcare staff members performing their services accurately in a very good way for citizens health and safety.

\section{Methodolgy}

\subsection{Study design}

The study design was a descriptive quantitative analysis because the research looks to collect a detailed information a cross-sectional with correlative elements to measure and exploring related factors, aspects and prediction. The researcher gives snapshot of the study population characteristics at specific point in time, to reach the intended findings. ${ }^{[5,6]}$

\subsection{Population and Sample}

The study population included health professional, specifically (Physician, Nurses, Pharmacist and Allied healthcare personnel) all of them working in primary healthcare centers in Dammam city, Kingdom of Saudi Arabia. Total number of manpower working at primary healthcare centers in Dammam city were 1,200 member, according to the statistics of the Ministry of Health in KSA, 148 of them are Physician, 387 Nurses, 54 Dentist's doctor, 59 Pharmacist, and Allied health personnel total were 157 which include 15 lab specialist, $20 \mathrm{X}$-ray specialist and 57 dental health specialist.

The sample size determined using reliable statistical calcu- lation formula which was (300). Out of the total population size of the health professionals from the Primary Healthcare centers in Dammam, which were 1,200 as stated herein above, the sampling size where the study applied to them were (300) health professionals without administration employees, the sample was calculated using specific formula, as follows: $s s=Z^{2} *(P) *(1-P) / C^{2}$

The below parameters:

-Confidence Level: 95\%.

-Confidence Interval: 5\%.

-Population: 1,200.

A representative stratified sampling method considered, the following inclusive criteria: both sex (male and female) selected out of the study population. In this sampling plan, the total population is divided into these groups and a representative sample of the groups selected. Moreover, Stratification is the process of dividing numbers of the population into homogeneous subgroups for sampling. The strata should be mutually exclusive: every element in the population must be assigned to only one stratum. ${ }^{[7]}$

\subsection{Setting}

This study conducts at primary health care centers in Dammam City, Kingdom of Saudi Arabia. The study settings selected according to cluster random sampling technique centers in Dammam City to ensure choosing a sample representing the different primary healthcare sectors within the city (Eastern, Western, Southern, Northern, and Central). The selection consider randomization so that the study setting can be determined more accurately without bias, the sample taken from 8 primary health centers selected out of (30) primary healthcare centers in Eastern City.

\subsection{Ethical consideration}

Ethical approval obtained from Research Committee at King Saud University in Dammam City. The ethical approvals to collect the data obtained from Plan research Department in Eastern province and from the General Director of health affairs in eastern province. Each participant got an information sheet for his/her participation in the study; any participants have the right to ask questions or withdraw from the study at any time. Each participant assigned a digital code to keep anonymity. Each participant signed a consent in Arabic form to participate in the study. The responses from different participants kept secure, only the researcher and the supervisor have the right to access the data in order to keep confidentiality.

\subsection{Procedure}

Official permission from the university administration obtained; the study was approved by the deanship for graduate 
studies at King Saud University. Obtaining validity and reliability test for the developed tool through expert panels and statistical analysis. A study survey done in order to test the research condition visibility an applicability, also, the study followed ethical aspects. Data collection setting was done by the researcher; the statements distributed by hand after obtaining written consent from participants, and acknowledging the subject's aims and all issues related to the research study, in order to allow the sample members, participate freely. The statements was collected after giving enough time to the participant responses which around fifteen to twenty minutes, and this was during the period from 01 April 2018 to 25 June 2018.

\subsection{Instruments}

The data was collected using Arabic version scales.

The tool comprises six parts consists of:

1) The personal profiles of the research participants in terms of age, gender, marital status and numbers of family members.

2) The social specification's profiles of the research participants in terms of education level, position type as per employment level, experience, monthly income, hours of work per day.

3) If the research participants suffering from disease.

4) If the research participants practicing and habit.

5) If the research participants attended training courses.

6) Job related Psychosocial and work environment risk aspects in primary health care included in statements directed to the current professionals' employees of healthcare center ${ }^{[8]}$ The statement adopts a Likert Scale, scoring as following: $($ Never $=1$, Seldom $=2$, Neutral $=3$, Often $=4$, Always $=5)$ This part focus on three main areas such as psychosocial, social and work environment. In order to give a clear meaning of the scores calculated by the scale, the range calculated in the scale where the range $=5-1=4$, by dividing the range by the numbers of categories (5) resulted $4 / 5=0.8$ which means the length of each category of four scales, then the length of the category is added to the lowest grade of the scale. So, the first category is produced to $1-1.8$ by adding the length of the highest limit for the category to produce the second category and so on for the rest of the categories.

\subsection{Reliability and validity \\ 2.7.1 Validity}

The validity of internal consistency of the statements was tested using Pearson correlation coefficient between the scores of each item in the statements. The total scores for all items in each table show the result of items correlation generally and by looking at Table 1, it shows that all coefficients of the items correlation with the Psychiatric aspects scale which are significant and has value at the level of .01 and .05 except two items this means there is no internal consistency and the overall factorial structure of the scale is holding. Moreover, Table 2 shows the correlation between social aspects scale and it is items, all statements are significantly correlated with the total score of the scale. Table 3 also provides clear picture that all items are significantly correlated with the work environment aspects scale and all items are significantly correlated with the scale.

\subsubsection{Reliability}

The reliability of the scales' items has been tested through the overall items using Cronbach's Alpha coefficient. Table 4 shows that the vital or physical aspects is .886 which is high significant value, and the reliability concerning the psychological aspects scale is significant value (.823) and its high, the same for the social aspects scale alpha value is .839 which is considered significant value. Moreover, the work environment aspects are considered significant value (.802) Therefore, entire items values are reliable and could be used in the analysis of this study results. There is a great degree of consistency and stability in this study instrument, which means the study is reliable, to the extent that if the scale measurements repeated, it will give the same result. Hence, the scale measurements were conducted under constant conditions.

\subsection{Statistical analysis}

The statements were calculated to figure out the results of the psychological aspect, the social aspects and the work environment aspects, variables were described using frequency distribution for categories stating the means and the standard deviations values according to the objectives and the study sample demographic characteristics to rank the items based on the point of view of the sample. Pearson's correlation coefficient: to reveal the validity of the internal consistency of the study instrument and to assess correlation between demographic characteristics and bio-psycho social and cultural aspects. Cronbach's alpha, to measure the reliability of the study instrument.

Statistical methods used: is the Statistical Package Survey System (SPSS) version 23. In addition to Pearson's correlation coefficient test.

\section{STUDYS FINDINGS}

\subsection{Social-demographic characteristics for health pro- fessionals}

Explore the data to know the nature of the socialdemographic background for the health professionals to give us a better understanding of the subjects and help us answers the questions. 
Table 1. Correlation of each item with the psychiatric aspect

\begin{tabular}{|c|c|}
\hline Validity of the Psychiatric Aspect & Correlation Value \\
\hline Does your work put you in emotionally disturbing situations? & $0.407^{* *}$ \\
\hline Do you have to relate personal problems to other peoples as part of your work? & $0.291 * *$ \\
\hline Is your work emotionally demanding? & $0.420^{* *}$ \\
\hline Do you get emotionally involved in your work? & $0.389 * *$ \\
\hline Are you required to treat everyone equally, even if you do not feel like it? & $0.420 * *$ \\
\hline Does your work require you to hide your feelings? & $0.302 * *$ \\
\hline Do you require to be kind towards everyone - regardless of how they behave? & $0.267^{* *}$ \\
\hline Does your work require you to be initiative? & $0.450 * *$ \\
\hline Do you have any possibility to learn new things through your work? & $0.384 * *$ \\
\hline Can you use your skills or expertise in your work? & $0.425^{* *}$ \\
\hline Does your work give you any opportunity to develop your skills? & $0.511^{* *}$ \\
\hline Is your work meaningful? & $0.367^{* *}$ \\
\hline Do you feel that the work you do is important? & $0.361^{* *}$ \\
\hline Do you feel motivated and involved in your work? & $0.536^{* *}$ \\
\hline Do you enjoy telling others about your place of work? & $0.469 * *$ \\
\hline Do you feel that your place of work is of great personal importance to you? & $0.444 * *$ \\
\hline Would you recommend a good friend to apply for a position at your workplace? & $0.414^{* *}$ \\
\hline At your work place, are you informed well of important decisions, changes, or plans for future? & $0.491^{* *}$ \\
\hline Do you receive any information you need in order to do your work well? & $0.529 * *$ \\
\hline Is your work recognized and appreciated by the management? & $0.414 * *$ \\
\hline Are you treated fairly at your workplace? & $0.401^{* *}$ \\
\hline Do you feel to be unemployed nearly? & $0.146^{*}$ \\
\hline Does the new technology make you redundant? & -0.048 \\
\hline Is it being difficult for you to find another job if you became unemployed? & 0.054 \\
\hline Do you being transferred to another job against your will? & $0.157^{* *}$ \\
\hline Have you become very nervous person due to your job? & $0.335^{* *}$ \\
\hline Have you felt so down in the dumps that nothing could cheer you up? & $0.298^{* *}$ \\
\hline Have you felt calm and peaceful? & $0.255^{* *}$ \\
\hline Have you felt downhearted? & $0.324 * *$ \\
\hline Have you become a happy person? & $0.337^{* *}$ \\
\hline Do you refuse to speak with anyone/or leave him while talking to you? & $0.407 * *$ \\
\hline Do you feel unable to stand dealing with other people? & $0.410^{* *}$ \\
\hline Do you feel you have no time to relax or enjoy yourself? & $0.360^{* *}$ \\
\hline Do you find any difficulty to feel happy? & $0.389 * *$ \\
\hline Do you feel comfort through eating? & $0.360^{* *}$ \\
\hline Do you become a bit touchy? & $0.466^{* *}$ \\
\hline Do you lacked to be initiative? & $0.320^{* *}$ \\
\hline Do you feel any harassment during your duty performance at a Healthcare center? & $0.214^{* *}$ \\
\hline
\end{tabular}

**Correlation is significant at the .01 . ${ }^{*}$ Correlation is significant at the .05 .

\subsubsection{Part1: Personal data}

Table 5 shows that $54.3 \%$ of the subjects were female and $45.7 \%$ were male.

Table 6 shows that $47 \%$ of the subjects were in the age group
(31-40) then $27 \%$ comes next for which their age group was less than 30 .

Table 7 shows that $77.7 \%$ of the health professionals' social status was married, and $18 \%$ were single. 
Table 2. Correlation of each item with the social

\begin{tabular}{lc}
\hline Validity of the Social Aspect & Correlation Value \\
\hline How do you often seek help and support from your colleagues & $.734^{* *}$ \\
To what extent your colleagues willing to listen to your work-related problems? & $.699^{* *}$ \\
How do your colleagues talk to you about your success in doing your work properly? & $.661^{* *}$ \\
Does your direct superior ready to listen to your work problems? & $.772^{* *}$ \\
How do you often seek help and support from your direct superior? & $.803^{* *}$ \\
How does your superior often talk with you about your work performance? & $.785^{* *}$ \\
\hline
\end{tabular}

**Correlation is significant at the $.01 .{ }^{*}$ Correlation is significant at the .05 .

Table 3. Correlation of each item with the work environment

\begin{tabular}{ll}
\hline Validity of the Work Environment Aspects & Correlation Value \\
\hline Do you have to work very fast? & $0.453^{* *}$ \\
Do you work at a high pace throughout the day? & $0.510^{* *}$ \\
Is it necessary to keep working at a high pace? & $0.482^{* *}$ \\
Do you have to keep your eyes on lots of things while you work? & $0.414^{* *}$ \\
Does your work require you to remember a lot of things? & $0.507^{* *}$ \\
Does your work demand you to coming up with new ideas? & $0.599^{* *}$ \\
Does your work require you to make difficult decision? & $0.672^{* *}$ \\
Do you face any ethical influences concerning your work? & $0.617^{* *}$ \\
Do you have a word to choose specific staff to work with? & $0.631^{* *}$ \\
Do you complain about the work quantity assigned to you? & $0.389^{* *}$ \\
Do you enforced to do what you do at work? & $0.453^{* *}$ \\
Does your work vary or constant? & $0.475^{* *}$ \\
Do you have to do the same thing over and over again? & $0.340^{* *}$ \\
Do you feel that your work drains your energy and it has a negative effect on your private life? & $0.482^{* *}$ \\
Does your friend or family tell you that your work is too much? & $0.515^{* *}$
\end{tabular}

**Correlation is significant at the .01 .

Table 4. Reliability of the aspects

\begin{tabular}{ll}
\hline Scale & Cronbach's Alpha value \\
\hline The psychological aspect & 0.823 \\
The social aspects & 0.839 \\
The work environment aspects & 0.802 \\
Total & 0.886 \\
\hline
\end{tabular}

Table 5. Gender

\begin{tabular}{lll}
\hline Gender & Frequency & Percent \\
\hline Male & 137 & 45.7 \\
Female & 163 & 54.3 \\
Total & 300 & 100 \\
\hline
\end{tabular}

The psychosocial aspects encountered by health professionals in work environment has been divided into psychiatric and work environment and more. Initially, the psychological aspects were reported by health care professional.
Table 6. Age groups of participants

\begin{tabular}{lll}
\hline Age & Frequency & Percent \\
\hline less than 30 & 81 & 27 \\
$31-40$ & 141 & 47 \\
$41-50$ & 39 & 13 \\
More than 50 & 5 & 1.7 \\
Missing & 34 & 11.3 \\
Total & 300 & 100 \\
\hline
\end{tabular}

Table 7. Marital status

\begin{tabular}{lll}
\hline Marital status & Frequency & Percent (\%) \\
\hline Married & 233 & 77.7 \\
Single & 54 & 18 \\
Widow & 2 & 0.7 \\
Divorced & 11 & 3.7 \\
Total & 300 & 100 \\
\hline
\end{tabular}

The scale statements, which include 38 statements used to 
explorer the coefficient correlation as per Pearson Test. Table 8 shows the analysis of the psychological aspects of health professionals, the overall value of the mean was 3.38. It indicates that the psychological aspects often happening as the overall mean fall in the category. In addition to that, when we go into details and sub-scales of the psychosocial aspects, we found that the statements are ranked within each sub-scale to show which statement have more agreement than the other.

In sub-scale emotional demands the overall mean is 3.38 which fall into the category and the statement "Do you have to relate to other people's personal problems as part of your work" has the highest mean (3.78) which indicate that this item was commonly happen for health professionals. Then comes in second the statement "Does your work put you in emotionally disturbing situations" with mean (3.43).

Then comes in third statements "Do you get emotionally involved in your work" with mean (3.25). Psychological aspects of Emotional demands, to measure this sub-scale the statement from 1-4.

This sub-scale demands for hiding emotions the overall mean (4.11) which fall into the category and Statement "Do you required to be kind and open towards everyone - regardless of how they behave" the statement has the highest mean (4.38) which indicate that this item is most common for health professionals in this sub-scale, then comes in second the statement "Are you required to treat everyone equally, even if you do not feel like it" with mean (4.03). Then comes in third statements "Does your work require that you hide your feelings "its mean (3.93), to measure this sub-scale the statement from (5-7).

Moreover, Sub-Scale Possibilities for development the overall mean was (4.09) which fall into the often category and Statement "Do you use your skills or expertise in your work" it has the highest mean (4.27) which indicate that this item most common to happen for health professional in this subscale, then comes in second the statement "Do you have the possibility of learning new things through your work" with mean (4.24). Then comes in the third statements "Do you feel that the work you do is important" with mean (4.24). to measure this sub-scale the statement from (8-11).

In addition, Sub-Scale Meaning of work the overall mean is (3.95) which fall into the often category and Statement "Is your work meaningful" had the highest mean (4.36) which indicate that this item is the most common to happen for health professional in this sub-scale, then comes in second the statement "Do you feel motivated and involved in your work" with mean (3.75). to measure this sub-scale the statement from (12-14).
Moreover, Sub-Scale Commitment to the workplace the overall mean was (3.63) which fall into the often category and Statement "Do you enjoy telling others about your place of work" has the highest mean (3.89) which indicate that this item most common to happen for health professional in this sub-scale, then comes in second statement "Would you recommend a good friend to apply for a position at your workplace" with mean (3.56). to measure this sub-scale the statement from (15-17).

Moreover, Sub-Scale Ability to plan the overall mean was (3.85) which fall into the often category and Statement "Do you receive all information you need in order to do your work well" has the highest mean (3.94) which indicate that this item is the most common to happen for health professional in this sub-scale, then comes in second statement "At your work place, do you informed with important decisions, changes, or plans for the future" with mean (3.76). to measure this sub-scale the statement from (18-19)

Also, Sub-Scale Recognition the overall mean was (3.65) which fall into the often category and Statement "Is your work recognized and appreciated by the management" has the highest mean (4.00) which indicate that this item most common to happen for health professional in this sub-scale, then comes in second the statement "Are you treated fairly at your workplace" with mean (3.29), to measure this subscale the statement from (20-21) to measure this sub-scale the statement from (20-21).

Also, Sub-Scale security in job the overall mean was (1.64) which fall into the often category and Statement "It being difficult for you to find another job if you became unemployed" had the highest mean (1.714) which indicate that this item most common to happen for health professional in this sub-scale, then comes in second the statement "Becoming, unemployed" with mean (1.652). to measure this sub-scale the statement from (22-25)

Also, The Sub-Scale Mental health of the psychosocial aspects of how much of upsets, past 4 weeks the overall mean was (2.99) which fall into the natural category and Statement "Have you felt so down in the dumps that nothing could cheer you up" has the highest mean (3.75) which indicate that this item most common to happen for health professional in this sub-scale, then comes in second the statement "Have you felt downhearted and blue" with mean (3.52). to measure this sub-scale the statement from (26-30).

Also, The Sub-Scale Mental health of the psychosocial aspects of how well the descriptions fit your situation during the past 4 weeks scale items the overall mean was (2.84) which fall into the natural category and Statement "I have been a bit 
touchy" has the highest mean (3.15) which indicate that this item most common to happen for health professional in this sub-scale, then comes in second the statement "I have eaten for comfort" with mean (3.10). to measure this sub-scale the statement from (31-38).

Table 8 below shows the correlation result between demographical variables and psychological aspects, thus conclude that there is no significant correlation between any of the demographical variables and psychosocial aspects scale except marital status as find a significant positive correlation with psychological aspects scale $(0.132 *)$. Also, there is a significant negative correlation between the educational level with the psychological aspects $\left(-0.178^{* *}\right)$. In addition to that, there are negative correlation between length of experience and monthly income with psychological aspects $(-0.128 *)$ $(-.194 * *)$

Table 8. Correlation between health professional demographic characteristics variables and total score of psychological aspects

\begin{tabular}{ll}
\hline Correlation's test (Pearson) & Psychiatric aspect Correlation value \\
\hline Age & -0.098 \\
Sex & 0.037 \\
Marital status & $.132^{*}$ \\
Number of family members & -0.057 \\
Educational level & $-.178^{* *}$ \\
Occupation & 0.032 \\
Type of Recruitment & -0.017 \\
Length of Experience & $-.128^{*}$ \\
Monthly Income & $-.194^{* *}$ \\
Length of daily work hours & -0.053 \\
\hline *Correlation is significant at level .0 either for negative, positive or no correlation.
\end{tabular}

Secondly, the Psychosocial aspect related to work environment stated The sub-scale statements, which include (15) statements used to explorer the coefficient correlation as per Pearson Test. Table (10) show the analysis of the analysis of the work environment aspects of health professionals, the overall mean is (3.44) which indicate that work environment aspects of them are often happening as the overall mean fall in the category often. In addition, to the details of the subscales of the work environment aspects and statements are ranked within each sub-scale to show which statement have more agreement than the other.

In Sub-Scale Work pace the overall mean is (3.44) which fall into the often category and Statement "Do you have to work very fast" had the highest mean (4.06) which indicate that this item is the most common to happen for health professionals, then comes in second the statement "Do you work at a high pace throughout the day" with mean (3.49). to measure this sub-scale the statement from (45-47).
In addition, Sub-Scale Cognitive demands the overall mean was (4.02) which fall into the often category and Statement "Does your work require you to remember a lot of things" has the highest mean (4.28) which indicate that this item most common for health professionals in this sub-scale, then comes in second the statement "Does your work demand that you are good at coming up with new ideas" with mean (4.03). to measure this sub-scale the statement from (48-51).

Moreover, Sub-Scale Participation in work decisions the overall mean was (3.74) which fall into the often category and Statement "Do you influence the amount of work assigned to you" has the highest mean (4.16) which indicate that this item most common to happen for health professional in this sub-scale, then comes in second the statement "Do you have any influence on what you do at work" with mean (4.02). Then comes in third statements "Do you have a say in choosing who you work with" with mean (3.4). to measure this sub-scale the statement from (52-55).

Also, Sub-Scale Variation the overall mean was (4.04) which fall into the often category and Statement "Do you have to do the same thing over and over again" has the highest mean (4.16) which indicate that this item most common to happen for health professional in this sub-scale, then comes in second the statement "Is your work varied" with mean (3.92). to measure this sub-scale the statement from (56-57).

The Sub-Scale Work-family conflict the overall mean was (3.86) which fall into the often category and Statement "Does your friends or family tell you to work too much" has the highest mean (3.91) which indicate that this item most common to happen for health professional in this sub-scale, then comes in second the statement "Do you feel that your work drains so much of your energy that it has a negative effect on your private life" with mean (3.82). to measure this sub-scale the statement from (58-59).

Table 9 shows below the correlation result between demographical variables and Work environment aspects, thus we conclude that there is no significant correlation between any of the demographical variables and Work environment aspects scale. However, there are negative significant correlation between length of experience and monthly income with social aspects $\left(-.116^{*}\right)(-.162 * *)$.

Table 10 below explains the correlation coefficient of the statements as per Pearson Test with the overall result of the psychological aspect in relation with the sub-scale of the psychological and work environment of the study community. The researcher from the above-mentioned table noticed that the correlation coefficient of all statements were statistically significant at the level (.05) therefore, the researcher decided 
not to delete any statement or items from the scale items, with this decision the scale reaches its final contents for current study community, which consist of (38) statement to measure psychological aspects and (15) statement to measure the psychosocial aspect related to work environment, which characterized by validity and reliability in addition to the internal consistency of the study community.

\subsubsection{Part 2: Social Specification}

With respect to the education level $(50.7 \%)$ of health professional have diploma degree and (42\%) of them have bachelor degree. Concerning the intended health professional occupation, we found that (34.7\%) of them were nurses and (18\%) of them were doctors, $(20 \%)$ of the sample were allied health personal. Moreover, (16\%) of the study sample were Pharmacist. As for type of recruitment $(87.3 \%)$ of the sample were fixed function-civil and $(9 \%)$ were autonomous recruiting but only $(3.7 \%)$ of the sample selected were temporary function. In term of health professional length of experience, we found that $(52.3 \%)$ of them spent more than five years in the same job and (31.7\%) $1-5$ years and only (6\%) spent less than 1 year. Length of daily work hours was $(76.3 \%)$ spent $(8-10)$ hours a day and $(17.7 \%)$ spent less than (8) hours.

Table 9. Correlation between health professional demographic characteristics variables and total score of work environment aspects

\begin{tabular}{ll}
\hline Correlation as per Pearson Test & $\begin{array}{l}\text { Work environment aspect } \\
\text { Correlation value }\end{array}$ \\
\hline Age & -0.055 \\
Sex & -0.043 \\
Marital status & 0.006 \\
Number of family members & -0.099 \\
Educational level & -0.016 \\
Occupation & -0.014 \\
Type of Recruitment & 0.004 \\
Length of Experience & $-.116 *$ \\
Monthly Income & $-.162 * *$ \\
Length of daily work hours & -0.045 \\
\hline *Correlation is significant at level .01 either for negative, positive or no correlation.
\end{tabular}

Table 10. Correlation related to the psychological aspects and correlation related to the work environment

\begin{tabular}{|c|c|c|c|c|c|c|c|}
\hline \multicolumn{6}{|c|}{ Correlation related to the psychological aspects } & \multirow{2}{*}{\multicolumn{2}{|c|}{$\begin{array}{l}\begin{array}{l}\text { Correlation related to the } \\
\text { work environment }\end{array} \\
\text { Work pace }\end{array}$}} \\
\hline \multicolumn{2}{|c|}{ Emotional demands } & \multicolumn{2}{|c|}{ Commitment to workplace } & \multicolumn{2}{|c|}{$\begin{array}{l}\text { Mental health how well these } \\
\text { descriptions fit your situation }\end{array}$} & & \\
\hline Item & correlation & Item & correlation & Item & correlation & Item & correlation \\
\hline 1 & 0.458 & 15 & 0.346 & 31 & 0.343 & 45 & 0.616 \\
\hline 2 & 0.258 & 16 & 0.431 & 32 & 0.331 & 46 & 0.342 \\
\hline 3 & 0.371 & 17 & 0.411 & 33 & 0.378 & 47 & 0.456 \\
\hline 4 & 0.373 & \multicolumn{2}{|c|}{ Ability to plan } & 34 & 0.417 & \multicolumn{2}{|c|}{ Cognitive demands } \\
\hline \multicolumn{2}{|c|}{ Demands for hiding emotions } & 18 & 0.304 & 35 & 0.470 & 48 & 0.364 \\
\hline 5 & 0.361 & 19 & 0.335 & 36 & 0.440 & 49 & 0.411 \\
\hline 6 & 0.416 & Recog & & 37 & 0.461 & 50 & 0.365 \\
\hline 7 & 0.346 & 20 & 0.534 & 38 & 0.692 & 51 & 0.357 \\
\hline \multicolumn{2}{|c|}{ Possibilities for development } & 21 & 0.520 & & & \multicolumn{2}{|c|}{ Participation in work decisions } \\
\hline 8 & 0.326 & Securi & & & & 52 & 0.421 \\
\hline 9 & 0.374 & 22 & 0.475 & & & 53 & 0.325 \\
\hline 10 & 0.437 & 23 & 0.498 & & & 54 & 0.354 \\
\hline 11 & 0.475 & 24 & 0.538 & & & 55 & 0.451 \\
\hline \multicolumn{2}{|c|}{ Meaning of work } & 25 & 0.566 & & & Variati & \\
\hline 12 & 0.495 & \multicolumn{4}{|c|}{$\begin{array}{l}\text { Mental health of the } \\
\text { psychosocial aspects of how } \\
\text { much of Upsets, past } 4 \text { weeks }\end{array}$} & 56 & 0.626 \\
\hline \multirow[t]{2}{*}{13} & \multirow[t]{2}{*}{0.427} & 26 & 0.457 & & & 57 & 0.415 \\
\hline & & 27 & 0.613 & & & 58 & 0.375 \\
\hline \multirow{3}{*}{14} & \multirow{3}{*}{0.421} & 28 & 0.316 & & & 59 & 0.334 \\
\hline & & 29 & 0.339 & & & & \\
\hline & & 30 & 0.327 & & & & \\
\hline
\end{tabular}




\subsubsection{Healthcare professionals suffer from diseases affect-} ing their performance

The health professionals are suffering from various kinds of diseases, we found that $(29.3 \%)$ of them have pressure and $(0.7 \%)$ of them have diabetes and $(70 \%)$ have no diseases.

\subsubsection{Part4: Practicing the following habits}

We found that $(64 \%)$ of the healthcare professionals practicing sports, and $(66.2 \%)$ of them eats healthy food, also $(54.9 \%)$ of them sleeps sufficient hours, and $(60.2 \%)$ of them don't smoke, indicating that these habits affected negatively or positively upon the work performance and then on their visitor's health too.

\subsection{The psychological aspects reported by health care professional}

The analysis of the psychological aspects of health professionals, the overall mean is (3.38) which indicate that psychosocial aspects of them are often happening as the overall mean in the category.

The sub-scale emotional demands, the overall mean is (3.38) which fall into the category and statement "Do you have to discuss your personal problems with other people as part of your work" the consequence result was highest mean of (3.78) which indicate that this item is the most common to happen for health professionals. Sub-scale commitment to the workplace the overall mean is (3.63) which fall into the category and statement "Do you enjoy telling others about your place of work" the consequence was highest mean of (3.89).

The sub-scale job in security the overall mean was (1.64) which fall into category and statement "Is it being difficult for you to find another job if you became unemployed" the highest mean were (1.714) The sub-scale of mental health of the psychosocial aspects of how well the descriptions fit your situation during the past 4 weeks scale items the overall mean was (2.84) which fall into the natural category and statement "I have been a bit touchy" expressed in the highest mean of (3.15) which indicate that this item is very common to happen for health professional in this sub-scale.

\subsection{The social aspects reported by health care profes- sionals}

The analysis of the social support from colleagues of health professional scale items, the overall mean is (3.95) which indicate that the social support from colleagues of health professional often to happen as the overall mean fall in the category often. The highest statement was "How often are your colleagues willing to listen to your work-related problems" with mean (4.03) The analysis of the social support from supervisor of health professional scale items, the overall mean is 4.16 which indicate that the social support from supervisor of health professional often to happen as the overall mean fall in the category often.

\subsection{The psycho social aspect related to work environ- ment stated by the study participants}

The analysis of the work environment aspects of health professionals, the overall mean was (3.44) which indicate that work environment aspects of them often happening as the overall mean fall in the category. The work environment aspects and statements are ranked within each sub-scale to show which statement have more agreement than the other. In Sub-Scale Cognitive demands the overall mean was (4.02) which fall into the often category and Statement "Does your work require you remember a lot of things" has the highest mean (4.28) which indicate that this item most common for health professionals in this sub-scale.

\section{Discussion}

Healthcare services in demand for population health, and health professionals will offer the best if they work in a good work environment. They will acquire more qualifications and experiences by practicing. If healthcare staff face psychosocial problems, it will prevent their efforts and increasing their burdens. Therefore, this research aims to figure out and to explore these hinders then to suggest some methods to solve it, for better health life. This part consists of demographic data discussion, stating the psychosocial issues in the healthcare work environment, in order to identify the top psychosocial challenges facing healthcare providers, and affected patients and families negatively. ${ }^{[10]}$

As stated, health professionals at primary health care level are often subjected to influence of stress due to working conditions which creates too much pressure and affected upon the staff health and capability to offer better care for client. $^{[11]}$

For social-demographic females constitute high ranks than males (54.3\%). The staff who hold diploma degree in health professional specialization were $(50.7 \%)$ and who are married were $(77.7 \%)$. These findings were supported by other studies performed in the similar fields such as the study done in Florida 2010, $(69.5 \%)$ of the sample participant were women $^{[12]}(47 \%)$ of them were (31-40) then male was (27\%) comes next for which their age group was (less than 30). Also, similar study supporting current study performed in Iraq at which the participants females age was between (20 to 39) years old. ${ }^{[13]}$ In addition to that, the study participants who have (3-5) person of family member affecting their job performance, their percentage was $(52.3 \%)$. While the staff members in healthcare who have (4 to 5) members affecting 
their job performance with percentage of $(53.3 \%) .{ }^{[14]}$ These results indicating that (Family members, gender) affecting positively, if the staff has a family consist of low family member, also female efforts were higher than males in term of gender as we found that (34.7\%) of the subjects were female nurses. ${ }^{[19]}$ The participants complain during the study for the length of daily work hours. They spent (8-10) hours per day in the work. Taking in to account that in primary care center all over the Saudi Arabia daily work hours must not exceeded over (8) hours per day, according to the labor office regulations.

An international study review suggests that managers must find ways to address issues of excessive workloads, irregular shifts and long working hours, as these matters have been found as major predictions of job dissatisfaction, high levels of burnout among healthcare workers in primary health care center. ${ }^{[15]}$

In this study, to detect the psychological aspects the researcher started with emotion which considered as important element in relation to personal and professional problems in work which has the highest mean of (3.78\%) indicating that this item most common to happen for health professionals. These results were supported by research study performed at work which concluded that the emotional demand one of the leading scales that affect the employees' attitude with a mean of $(4.76 \%)$ for behavioral part emotional factors which relations achieved the first two highest ranks Job, ${ }^{[16]}$ insecure the items with highest level of (1.714). Whenever an employee works in a job, he wants to feel safe and doesn't want to be buzzard, some participants in this research have a fear to lose their jobs. While it's not easy to find another job, they feel insecure due to the psychosocial and ethical problems facing them in their jobs, there is another study also supported the same results related to the job insecurity, strain and demand which showed positive correlation between $(0.242$ to -0.122$)$ during the skill discretion and decision latitude. ${ }^{[17]}$

With respect to the mental health which have higher effect in work, the statement starts the mental health expression stating to what extent you feel mentally disturbed during the past (4) weeks, the statement which has highest mean results was "I have been a bit touchy" it has mean of (3.15\%). There was a supportive study conducted at King Khalid University in KSA explained that, mental health was an important issue in the workplace, particularly in developing countries. The result proved that poor mental health work environment affected negatively on the services offered. Accordingly, the statistic result of mental health of the healthcare providers has significant positive correlation with "quantitative demands". Also, job performance with family conflict" and "emotional demands “in all country's nationals and expatriates was $p<$ $.01^{[18]}$ The social aspects reported by healthcare professionals, was the social support of their colleagues the statement was "How often are your colleagues willing to listen to your work-related problems" the result comes with mean of (4.03).

One of the most important factors was that long working hours at healthcare centers definitely brought fatigue to employees, and this lead them to feel indignant. In such situation the affected member of the staff will seek support of his colleagues. It's clear that if healthcare employee felt work place as his/her second home, he/she will collaborate with his colleagues. They will become more positive, useful towards his clients, and prolong his stay in his work for years.

The second item is the social support from supervisors. The highest statement was "Do your superior willing to listen to your problems at work" the outcome result with mean of (4.11), and the second item was "How do you often seek help and support from your immediate superior" the outcome was mean of (4.06). These results showed close relationship between employees' satisfaction and their supervisor's support. Accordingly, supervisors must be fair in their treatment, communication within the work environment, as well as with their staff, in order to ensure that they behave with respect and ethics, to shed light on behavioral components on work environment and is significant for staff.

Almost all attendees strongly agree in their replies stating that relationship with supervisors who have fair treatment and communications was important. Co-worker and supervisor support showed positive correlation of (0.109 to 0.116). The psychosocial factors were significantly related to several aspects of self-evaluation. Supervisor support was associated with intention to extend work. ${ }^{[19]}$ Therefore, supervisors support was strongly significant and statistically correlated with "Influence at work", "Social support from colleague", and "Social support from supervisors", was important and means a lot at work encouraging the employee to be loyal and committed to the workplace, "Predictability" towards the staff with poor mental health was $p<.001 .^{[20]}$

Concerning the psychosocial aspect related to the work environment stated by the study statements. In fact, the result came to support the researcher expectation and assumption. Essentially, there are so many psychosocial work environment problems facing healthcare officials. In comparing the same topic in different area of the work environment there was one Swedish research result supporting this point. It concluded that "(workers, union health and safety representatives are increasingly listing issues such as downsizing, understaffing, mandatory overtime, push for production, cross-training, multi-tasking, and work over load or work 
faster without rest time)" these elements considered as key factors causing or contributing to pressure, illness and stress in workplaces. ${ }^{[21]}$

In this study which include five sub-scale, beginning work pace (speed) "Do you have to work very fast" the mean achieved highest level of (4.06) which indicate that this item occurred commonly and repetitively to the health professionals.

Consequently, the psychosocial problems and work pressure due to the subsided causes, whether from workload, from patients or bad treatment of superior managers in the work place, all of this issue will lead the individual who serve at health sector to abandon his job, seeking for better work place to find respect in dealing and enjoyment. ${ }^{[2]}$ In this point several studies set to investigate the relationship between social and psychological work environment. These studies revealed the staff issues in particular staff shortages, resulted due to high workloads and lack of job satisfaction. In brief, the study findings show that psychosocial work factors are important correlates for both intentions and job satisfaction. ${ }^{[23]}$ The statement about the work decisions "Did you affected by the workload assigned to you" the mean value was (4.16) which indicate that this item commonly happened for health professional in healthcare sectors. Indeed, participating in decision making at work, has effects on the services provided. Over the last several years, other studies and survey performed over 100,000 employees in companies throughout the United States. Proved that there was a direct correlation between employee's involvement in decision-making in their department and their overall moral, motivation, and satisfaction with their jobs. Companies and departments who have a higher level of employees involvement in decision-making show higher levels of employee motivation and satisfaction. ${ }^{[24]}$

The statement of variation "do you have to do the same thing over and over again" intended to measure the work repetition, its mean was (4.16) which indicate this item was happen commonly for health professional in this sub-scale. The most important issue received during the survey and analysis of the study data was that (daily work is frequent and nursing staff in particular are doing the same thing over and over) and this is enough reason to leave the job, because work environment will not help you as staff member to improve your work skills. The researcher found that nurses were changed weekly inside departments at the same center, job instability lead them to change their work place continuously, accordingly, lack of enough staff members in healthcare centers will occur..

One of the most important studies confirms that human mind responds is smarter in case of multiple tasks more than repetitions of the same tasks daily. The human brain by its nature is able to exceed modern computers on multiple computational demands (e.g., language, planning) using a small fraction of energy. Therefore, it will be affected psychosocially due to the repetitions and lack of renewal, how the brain can be so efficient is compounded by recent evidence that all brain regions are constantly active, the brain's network configuration varies based on current task demands. Thus, the external daily situation in healthcare center affected positively or negatively on the employee internal brain status depending on its nature. ${ }^{[25]}$

The last statement was work-family conflict stated as follows "Do your friends or family tell you that you work too much" its mean was (3.91) which indicate that this item most common to happen for health professional in this sub-scale. A study on the effects of work overload, work-family conflict on job performance and exhausted functions were full mediator concerning the effects of the work overload or workfamily conflict on job performance. Specifically, employees who have heavy workloads they were unable to establish a balance between their work and family issues. Their roles are emotionally exhausted. ${ }^{[26]}$ Another study show that the poor mental health had strong statistical significant positive correlation with "quantitative demands"," work-family conflict", and "Emotional demands" in both country's nationals and expatriates health staff members. If there any correlations between social demographic profile, psychosocial and work environment of health care professional participating in this study, the study has found highest points in comparing between social demographic profile and psychosocial cases of healthcare providers in the work environment as per the professional participating in this study, beginning with the correlation between any of the demographical variables and psychological aspects.The result shows there is no significant correlation between any of the demographical variables and psychological aspects scale, except in marital status. There is a significant positive correlation with psychological aspects scale. Also, there was a significant negative correlation between the educational levels with psychological aspects. In addition to that, there is a correlation between length of experience and monthly income with psychological aspects.

This study contributes and justifies its present results by revealing the improvement of exposure to psycho social work factors such as (psychological demands, autonomy, support, and distributive justice) which associated with better mental health compared to unstable or unfavorable exposure to psycho social work factors in all older workers. 
Improvement in job performance was associated with better mental health in employees aged 55-64 years who have long work experiences, compared to unstable and unfavorable exposure to work performance. Improvement of exposure to support was associated with poorer mental health in men more than women, compared to the unstable or unfavorable exposure.

\section{Conclusion}

The study participants were mainly female, nurses and married. In work environment any acts lead to emotional disturbance, ethical situations or social violations are prohibited generally. Any positive psychosocial aspect potentiates healthcare staff members work experiences, whenever staff members found sociological or psychological support they need. Their job performance will increase and reflected on their patients' health. Therefore, psychosocial support is very important factor. It is obvious that stress, pressure and exhaustion experiences in work for long hours, will affected negatively as stated by the study participants.

\section{Recommendation and suggestions}

The researcher states recommendations clearly as related to the study problem, and addressed to facilitate any psychosocial problem facing healthcare staff members in their work environment, and to prevent its future occurrence for better work environment. For instance, we suggest that the concerned party must employ trained officers with special education, fully equipped with tools suit their tasks, to be able to detect any violation towards healthcare staff. Such staff must be able to classify the nature of any case whether its psychological, social, ethical, traditional or else, to record such violation to the concerned party, to repones accordingly as soon as possible and solve it immediately. This method should be applied initially, at one or two healthcare centers then maximized to the rest, to utilizes its usefulness and these efforts will prevent future problems occurrence definitely. There should be a regular audit visit to the healthcare centers, practiced by official party concerned with health issues, accompany with a team specialized in health aspects (Psychosocial) to see the work progress and to know the situation in centers and health services process.

\section{ACKNOWLEDGEMENTS}

I would like to thank and commend King Saud University for its support of the researchers, as well as Dr. Hammoud Al-Harbi (main supervisor) and Dr. Elham Fayad (assistant supervisor) for their continuous guidance and scientific support during the period of my research work.

\section{CONFLICTS OF INTEREST Disclosure}

The author declares that there is no conflict of interest.

\section{REFERENCES}

[1] World Health Organization. World Health Report 2012: working together for health. Geneva: WHO. 2015. Available from: http: //www.who.int/whr/2012/whr06pdf

[2] Minyan M, et al. The Iranian Version of the Copenhagen Psycho social Questionnaire (COPSOQ) for Assessment of Psychological Risk Factors at Work. 2017. Available from: https://journals.plos . org/plosone/articleid=10.1371/journal pone .0196450

[3] Ioana VP. Stress: Concepts, Theoretical Models and Nursing Interventions. American Journal of Nursing Science. 2015; 4(2): 45. https://doi.org/10.11648/j.ajns.s.2015040201.19

[4] Massoudi AH, Salah S, Hamdi A. The Consequence of Work Environment on Employees Productivity. IOSR Journal of Business and Management (IOSR-JBM). 2017; 19(1): 35-42. https : //doi.org/10.9790/487X-1901033542

[5] Levin KA. Study Design III: Cross-Sectional Studies'. EvidenceBased Dentistry. 2006; 7(1): 24-25. PMid:16557257 https ://doi. org/10.1038/sj . ebd. 6400375

[6] Lewandowski CM, New C, Clare M, et al. Guideline of Professional Classification and Registration for Health Practitioners'. The effects of brief mindfulness intervention on acute pain experience: An examination of individual difference. 2015.

[7] Boteh Z, Ridder A. Variance Reduction. Wiley Stats Ref: Statistics Reference Online. 2017. Available from: https://doi.org/10.1 002/9781118445112.stat07975

Published by Sciedu Press
[8] County K, et al. Factors Influencing Retention of Health Workers in Primary health care facilities, Kakamega County, Kenya. 2019 Available from: http://erepository.uonbi.ac.ke/handle/1 1295/6934. Abstract

[9] Elisheba MM, Sridharan J. Work Ability and It is Association with Psycho social Factors. International Journal of Innovative and Applied Research. 2014; 2(11).

[10] El-Masoud MA. Workplace Psychosocial Factors and Mental Health among a Sample of Expatriates and the Country's Nationals Who Working at King Khalid University, Saudi Arabia. Journal of Biology, Agriculture and Healthcare. 2013; 3(11): 122-32.

[11] Nielsen MB, Isrgheim K, Eid J. 2013. 'Relationships between Work Environment Factors and Workers' Well-Being in the Maritime Industry'. 2013.

[12] Bazzani, Ahmad. Demographic Factors and Their Relation to Fatigue and Mental Disorders in 12-Hour Petrochemical Shift Workers. 2015.

[13] Mandisa ZM. A conceptual model for improving working conditions in public PHCs in Mpumalanga Province. An occupational health and safety perspective [PhD thesis]. Department of Nursing Science, University of Limpopo (Medusa). 2015. Available from: https://www.researchgate.net/publication/313583156

[14] WHO/Europe. supports Member States in reforming primary health care within the framework of their overall health system reforms. 2017. Available from: 
http://www . euro. who.int/en/countries/Greece/new s/news/news?root_node_selection $=73611$

[15] Graham KR, Davies BL, Woodend AK, et al. Impacting Canadian public health nurses' ob. satisfaction. Canadian Journal of Public Health. 2011; 427-e431. PMid:22164552 https ://doi.org/10.1 $007 /$ BF03404193

[16] Deloitte Central Europe. Code of Ethics and professional conduct Deloitte. 2013. Available from: https://www2.deloitte.com/content/dam/Deloitte /global/Documents/About-Deloitte/central-europe/CE _Deloitte_CE_Code_Ethics_Conduct.pdf

[17] Karate OM. The Effects of Work Overload and Work-Family Conflict on Job Embeddedness and Job Performance the Mediation of Emotional Exhaustion'. IOSR Journal of Business and Management. 2015. Available from: http://iosrjournals.org/iosr-jbm/p apers/Vol16-issue1/Version-5/K016157580.pdf

[18] Bakker AB, Demerouti E. Job demands - resource theory. In C. Cooper and P. Chen (Eds.), Wellbeing: A complete reference guide (pp. 37-64). Chichester, UK: Wiley-Blackwell. Burnout at Work: A Psychological. 2014. Available from: https : //www.researchga te.net/publication/263809792

[19] Burnout_at_Work_A_Psychological_Perspective_an_edi ted_volume

[20] Haisrman's BM. The Association between Exposure to Psycho social Work Factors and Mental Health in Older Employees,3-Year
Follow-up Study. International Archives of Occupational \& Environmental Health. 2018; 91(1): 57-66. PMid:28921049 https : //doi.org/10.1007/s00420-017-1261-8

[21] Chamisa N, Karl P, Dragan I, et al. Effect of Personal and Work Stress on Burnout, Job Satisfaction and General Health of Hospital Nurses in South Africa. Health SA Gesundheit. 2017; 22: 252-58. https://doi.org/10.1016/j.hsag. 2016.10.001

[22] Razi A, Waheela M. Impact of Working Environment on Job Satisfaction'. Procedia Economics and Finance. 2015; 23(Octoisr2014): 717 25. https://doi .org/10.1016/S2212-5671(15)00524-9

[23] Browne P. The Relationship between Workplace Psycho social Environment and Retirement Intentions and Actual Retirement: A Systematic Review. European Journal of Ageing. 2018. PMid:30886562 https://doi.org/10.1007/s10433-018-0473-4

[24] Hofstetter H, Cohen A. The mediating role of job content plateau on the relationship between work experience characteristics and early retirement and turnover intentions. Pers Rev. 2014; 43: 350-376. https://doi.org/10.1108/PR-03-2012-0054

[25] Sokol MA, Son CK. Job Satisfaction, Burnout, and Stress among Pediatric Nurses in Various Specialty Unit is at an Acute Care Hospital. Journal of Nursing Education and Practice. 2014; 4(12): 115-24. https://doi.org/10.5430/jnep.v4n12p115

[26] Burnout_at_Work_A_Psychological_Perspective_an_edi ted_volume. accessed Jul 192018. 